Original article

\title{
Clinical profile of acute myocardial infarction in elderly patients
}

\author{
Lovleen C. Bhatia $^{\mathrm{a}, *}$, Ruchi H. Naik ${ }^{\mathrm{b}}$ \\ ${ }^{a}$ Department of Medicine, MM Institute of Medical Sciences Research, Ambala, Haryana, India \\ ${ }^{\mathrm{b}}$ Department of Medicine, Government Medical College and New Civil Hospital, Surat, Gujarat, India
}

\section{A R T I C L E I N F O}

Article history:

Received 1 April 2012

Accepted 29 July 2012

Available online 18 June 2013

\section{Keywords:}

Arrhythmia

Atypical presentation

Congestive cardiac failure

Dyspnea

Elderly

\begin{abstract}
A B S T R A C T
Context: The aim of study was to determine the difference in presentation, risk factors, complications, management and outcome of elderly and young patients with acute myocardial infarction (AMI).

Settings and design: Tertiary care center; prospective observational study.

Materials and method: The study included 200 consecutive patients with AMI admitted in the ICCU, in a tertiary care center in West India. The group I consisted of 107 patients aged equal to or above 65 years and the group II consisted of 93 patients aged below 65 years.

Statistical analysis: Two tailed student's $t$ test and Chi-square statistics (Fisher's test) for $P$ value.

Results: The male female ratio was 1.27:1 and 3.43:1 in group I and group II respectively. Atypical presentations were more likely in the elderly, with shortness of breath as the most common presentation (40.18\% versus $15.05 \% ; P<0.05$. Risk factors like hypertension, dyslipidemia and diabetes were equally present in both groups but obesity, smoking and family history of coronary artery disease was more prevalent in younger age group $(P<0.05)$. The elderly were significantly less frequently revascularized $(P<0.05)$. Time from symptom onset to hospital admission was significantly longer in the case of elderly patients $(P<0.05)$. The elderly were more likely to have complications of cardiac failure $(P<0.05)$ and arrhythmias especially atrio-ventricular (AV) blocks. The elderly were also less likely to receive betablockers $(P<0.05)$. In-hospital mortality was higher in the elderly $(P<0.001)$.

Conclusion: We conclude that the manifestations of AMI are more subtle in the elderly, with different risk factors.
\end{abstract}

Copyright $\odot$ 2013, SciBioIMed.Org, Published by Reed Elsevier India Pvt. Ltd. All rights reserved.

\section{Introduction}

The elderly with acute myocardial infarction (AMI) have been reported to present with more atypical symptoms. ${ }^{1,2}$ AMI is associated with significantly higher mortality in the elderly compared with the young, ${ }^{2-7}$ yet the elderly are treated less aggressively than the young. ${ }^{2}$ Thrombolytic therapy has the greatest effect in the elderly even though there is an increased risk of haemorrhagic stroke. ${ }^{8,9}$ The benefits of aspirin, angiotensin converting enzyme (ACE) inhibitors and beta-blockers in AMI have been substantiated in numerous trials, ${ }^{10}$ but their usage in elderly AMI patients may be lower than in younger patients. ${ }^{11}$ Because of the increasing burden on health care systems associated with MIs in the elderly, differences in clinical picture, and difficulties in dealing with elderly patients with myocardial infraction (MI), we analyzed the course of

\footnotetext{
* Corresponding author. C/o Surinderjit Singh Walia, 4-Dhaliwal Colony, Dr. Saronwala Street, Backside Rajindra Hospital, Patiala 147001, Punjab, India. Tel.: +919876960665.

E-mail address: lovleen_dr@yahoo.co.in (L.C. Bhatia).
}

AMI in patients hospitalized in the intensive cardiac care unit (ICCU) of the tertiary care hospital. The aim of study was to determine the difference in presentation, risk factors, complications, management and outcome of elderly patients with acute myocardial infarction and young patients with acute myocardial infarction.

\section{Materials and methods}

The study included 200 consecutive patients with AMI treated in the intensive cardiac care unit (ICCU) of the tertiary care hospital in Surat, India from October 2006 to September 2008. AMI was defined according to the European Society of Cardiology (ESC) definition $2000,{ }^{12}$ by the significant elevation of myocardial necrosis markers (Troponin-T or CK-MB two times the upper limit of normal level) in addition to a history compatible with MI, electrocardiographic abnormalities, or both. The history compatible with MI was defined as the presence of anginal chest pain lasting more than $30 \mathrm{~min}$. The electrocardiographic abnormalities were defined as: $1 \mathrm{~mm}$ or more ST segment elevation in contiguous leads; $1 \mathrm{~mm}$ or more ST segment depression; definite T-wave inversion; 
evolution of pathologic Q-waves ( $\geq 0.04 \mathrm{~s}$ ); or new onset left bundle branch block (LBBB). The patients were separated into 2 groups according to age. The study group (group I) consisted of 107 patients aged 65 or over (aged $65-95$ years; mean $73 \pm 6.8$ ) and the control group (group II) consisted of 93 patients aged below 65 years (aged 31-64 years; mean $47.2 \pm 7.3$ ). In this article, we have defined elderly patients as being 65 years or older. ${ }^{13}$ Subjects of stable and unstable angina were excluded. Subjects fulfilling the inclusion criteria were analyzed. Baseline clinical history, complications, risk factors of AMI and past illness were documented in a prescribed performa. A detailed clinical examination was carried out. Investigations included fasting and $2 \mathrm{~h}$ post meal blood sugar estimation, cardiac biomarkers (CPK-MB or Troponin-T), blood urea, lipid profile, AST levels, Chest radiograph, Two-dimensional Echocardiography and Doppler study done for LVEF and complications of myocardial infarction. Congestive cardiac failure at the time of presentation was graded as per Killip's classification. ${ }^{10}$ All patients received standard therapy according to the ESC standards and according to clinical setting. The complications like cardiogenic shock, heart blocks, arrhythmias at the time of admission were recorded. Ventricular premature beats (VPB) were graded as per Lown's grading system. ${ }^{14}$ Hypertension was defined according to JNC VII (the seventh report of the joint national committee on prevention, detection, evaluation, and treatment of high blood pressure) criteria ( 2 measurement values of blood pressure $\geq 140$ / $90 \mathrm{mmHg}$, or patient was on hypotension therapy before $\mathrm{MI}$ ). Dyslipidemia was defined according to ESC prevention guidelines, ${ }^{15}$ (total cholesterol $\geq 190 \mathrm{mg} / \mathrm{dl}$ and/or triglycerides $\geq 150 \mathrm{mg} / \mathrm{dl}$, or patient was on hypolipidemic therapy-statins/fibrates before MI). Obesity was defined based on the body mass index $\geq 30 \mathrm{~kg} / \mathrm{m}^{2}$. Diabetes mellitus (DM) was diagnosed if patient suffered from DM before MI. The patient was assumed to be an addictive smoker if he/ she smoked actively before MI. All episodes of ischemic heart disease and the episodes of invasive procedures in history were documented. Family history of coronary artery disease (CAD) is defined as any clinical atherosclerosis in the family diagnosed in females before 65 and in males before 55 years old. All the cases were followed up till satisfactory discharge from hospital or death for various events and complications.

\subsection{Statistical analysis}

Statistical analysis was carried out using SPSS software, and the mean values and frequencies of various risk factors (variables) were studied in the groups as a whole and individually in the two sub groups, namely AMI in elderly patients (group I) and AMI in young (group II). Continuous clinical characteristics in both groups were compared by unpaired $t$-test and categorical variables in both groups were compared by using Chi-square statistics (Fisher's test), data were presented in percentage and mean $\mu$ SD. A P value $<0.05$ was assumed to be statistically significant.

\section{Results}

The present study comprised of total 200 cases of acute myocardial infarction (AMI) of which 107 belonged to group I (age $>65$ years) and 93 belonged to group II (age $<65$ years). [Table 1] summarizes the study results.

First, clinical symptoms of MI differed in the elderly as compared to younger patients. Typical angina chest pain was the most common presenting symptom in both age groups, but more likely in the young than elderly patients $(81.76 \%$ versus $50.47 \%$; $P<0.05)$. Atypical chest pain $(28 \%$ versus $10.75 \%)$ or no chest pain $(21.49 \%$ versus $7.53 \%)$ was more commonly observed in elderly group as compared to younger age group $(P<0.05)$.
Dyspnea, palpitation, giddiness and syncope were reported more frequently by the elderly [Table 1]. Few elderly patients presented with abdominal pain, dental pain but the difference was not statistically significant. Also, electrocardiographic presentation differed in the elderly. ST elevation was less frequently detected in the elderly (56 $\{52.34 \%\}$ versus $62\{66.66 \%\} ; P<0.05$ ). The differences were statistically significant. LBBB and changes of NSTEMI tended to be more frequent in the elderly, but the differences did not reach statistical significance $(P>0.05)$ in our observations [Table 1].

The number of elderly subjects arriving within $6 \mathrm{~h}$ of chest pain was significantly less as compared to young subjects (51/107 i.e. 47.66\% Versus $62 / 93$ i.e. $72 \%, P<0.05$ ).

Assessment of risk factors revealed there were more women in elderly group (47/107) as compared to group I $(21 / 93)(P<0.05)$. The young AMI patients were more likely to be smokers $(43.01 \%$ versus $16.82 \% ; P<0.05)$ and obese $(17.2 \%$ versus $5.61 \% ; P<0.05)$ compared to the elderly patients. However, there was no difference between the two age groups with regard to the presence of hypertension, diabetes mellitus and dyslipidemia. A family history of coronary artery disease was common $(P<0.05)$ among young patients and in 37 (34.58\%) elderly patients no risk factor was found $(P<0.05)$ [Table 1].

Assessment of complications of AMI at the time of hospitalization revealed that $70(65.42 \%)$ cases from group I presented with congestive cardiac failure (CCF) at the time of admission in ICCU as compared to only 34 (36.56\%) cases in group II, which is statistically significant $(P<0.05)$ [Table 1 ]. In elderly group $32(29.9 \%)$ patients presented Killip's class III of congestive heart failure as compared to only $5(5.38 \%)$ in group I $(P<0.05)$ [Table 1 ]. Fifty three $(49.43 \%)$ cases from group I had arrhythmias during in hospital stay compared to only 28 (30.11\%) from group II $(P<0.05)$. AV block was seen in $22(20.56 \%)$ cases from elderly group as compared to $6(6.45 \%)$ cases from group I $(P<0.05)$ [Table 3]. Complete heart block was more commonly observed in elderly group $(13.08 \%$ versus $1.07 \%, P<0.05)$ as compared to group II. There was no difference between the two age groups with regard to occurrence of other complications like cardiogenic shock, recurrent MI, cerebrovascular accidents, bleeding complications and other arrhythmias (ventricular tachycardia or fibrillation, supraventricular tachycardia and atrial fibrillation). Forty eight $(51.61 \%)$ patients in younger age group had no complications as compared to elderly group where only 25 (23.36\%) had uncomplicated MI $(P<0.05)$ [Table 2].

Mortality was found to be significantly higher in elderly population group (I) than young population with AMI $\{30$ (28.04\%) versus 08 (8.6\%) $(P<0.05)$ \} [Table 3].

Thrombolytic therapy was considered in patients with STEMI or patients with new onset LBBB (68 patients in elderly and 69 patients in younger age group) and it was found that this therapy was under used in elderly group (I) only in 27 (39.7\%) cases as compared to $44(63.77 \%)$ in group (II) which was statistically significant $(P<0.05)$. Rest of patients had contraindications to thrombolytic therapy more so in elderly group but the difference was not found to be statistically significant in our study [Table 5]. Percutaneous transluminal coronary angioplasty (PTCA) was performed on 5 (4.67\%) and 16 (17.2\%) of groups I and II, respectively $(P<0.05)$. In elderly patients, PTCA and thrombolysis were done less frequently when compared to younger patients $[P<0.05$; Table 4]. Among the other drugs used in the treatment of AMI and its complications (aspirin, NTG, low molecular weight heparin LMWH, $\beta$-blockers, ACE inhibitors, and lipid lowering agents), only 18 (16.82\%) cases from elderly group (I) received $\beta$-blockers as compared to 56 (60.22\%) cases from group (II) which was statistically significant $(P<0.05)$. 
Table 1

Summary of study results.

\begin{tabular}{|c|c|c|c|}
\hline & Group 1 Elderly with AMI $(N=107)$ & $\begin{array}{l}\text { Group } 11 \text { Young with AMI } \\
(N=93)\end{array}$ & $P$ value \\
\hline Mean age in years & $73.0($ SD 6.8$)$ & $47.2($ SD 7.3) & $<0.05^{*}$ \\
\hline Male:Female & $1.27: 1(60: 47)$ & $3.43: 1(72: 21)$ & $0.0017^{*}$ \\
\hline Presentation within $6 \mathrm{~h}$ of onset of symptoms & $51(47.66 \%)$ & $67(72 \%)$ & $<0.05^{*}$ \\
\hline \multicolumn{4}{|l|}{ ECG changes } \\
\hline STEMI $^{\mathbf{a}}$ & $56(52.34 \%)$ & $62(66.66 \%)$ & $0.04^{*}$ \\
\hline NSTEMI $^{\mathrm{b}}$ & $39(36.45 \%)$ & $24(25.81 \%)$ & 0.127 \\
\hline Acute new onset $\mathrm{LBBB}^{\mathrm{C}}$ & $12(11.21 \%)$ & $7(7.53 \%)$ & 0.471 \\
\hline \multicolumn{4}{|l|}{ Presenting symptoms } \\
\hline Typical anginal chest pain & $54(50.47 \%)$ & $76(81.72 \%)$ & $0.0001^{*}$ \\
\hline Atypical chest pain & $30(28 \%)$ & $10(10.75 \%)$ & $0.0025^{*}$ \\
\hline No chest pain & $23(21.49 \%)$ & $7(7.53 \%)$ & $0.009^{*}$ \\
\hline Diaphoresis & $51(47.66 \%)$ & $45(48.38 \%)$ & 1 \\
\hline Breathlessness & $43(40.18 \%)$ & $14(15.05 \%)$ & $0.0001^{*}$ \\
\hline Nausea and or vomiting & 45 (42.05\%) & $33(35.48 \%)$ & 0.38 \\
\hline Palpitation & $16(14.95 \%)$ & $5(5.37 \%)$ & $0.0364^{*}$ \\
\hline Giddiness & $24(22.43 \%)$ & $7(7.5 \%)$ & $0.005^{*}$ \\
\hline Syncope & $11(10.28 \%)$ & $2(2.15 \%)$ & $0.022^{*}$ \\
\hline Altered sensorium & $11(10.28 \%)$ & $6(6.45 \%)$ & 0.44 \\
\hline Dental pain & $2(1.87 \%)$ & $0(0 \%)$ & 0.49 \\
\hline Abdominal pain & $4(3.74 \%)$ & $0(0 \%)$ & 0.12 \\
\hline Focal neurological deficit & $4(3.74 \%)$ & $0(0 \%)$ & 0.12 \\
\hline $\mathrm{CCF}^{\mathrm{d}}$ at time of presentation (Killip's classification) & $70(65.42 \%)$ & $34(36.56 \%)$ & $0.0001^{*}$ \\
\hline Killip’s Class I & $12(11.21 \%)$ & $11(11.83 \%)$ & 1.0 \\
\hline Killip’s Class II & $19(17.76 \%)$ & $15(16.13 \%)$ & 0.85 \\
\hline Killip's Class III & $32(29.9 \%)$ & $5(5.38 \%)$ & $0.0001^{*}$ \\
\hline Killip’s Class IV & $7(6.54 \%)$ & $3(3.23 \%)$ & 0.34 \\
\hline \multicolumn{4}{|l|}{ Risk factors } \\
\hline Hypertension & 46 (42.99\%) & $29(31.18 \%)$ & 0.1 \\
\hline Diabetes mellitus & $18(16.82 \%)$ & $16(17.2 \%)$ & 1.0 \\
\hline Smoking & $18(16.82 \%)$ & $40(43.01 \%)$ & $0.0001^{*}$ \\
\hline Dyslipidemia & $24(22.43 \%)$ & 19 (20.43\%) & 0.86 \\
\hline Obesity & $6(5.61 \%)$ & $16(17.2 \%)$ & $0.01^{*}$ \\
\hline Family history of $C A D^{\mathrm{e}}$ & $3(2.8 \%)$ & $21(22.58 \%)$ & $0.0001^{*}$ \\
\hline No above risk factor & 37 (34.58\%) & $12(12.9 \%)$ & $0.001^{*}$ \\
\hline
\end{tabular}

${ }^{*} P$-value $<0.05$ significant.

a STEMI = ST segment elevation myocardial infarction.

b NSTEMI = Non ST elevation myocardial infarction.

c $\mathrm{LBBB}=$ Left bundle branch block.

d $\mathrm{CCF}=$ congestive cardiac failure.

e $\mathrm{CAD}=$ coronary artery disease.

\section{Discussion}

The clinical picture of MI in elderly patients differs in many aspects as compared to younger patients. The factors affecting the course of MI in the elderly have not been studied in detail. The present study shows that with increasing age the preponderance of male among patients with AMI admitted to the hospital decreases and sex ratio becomes smaller. This possibly reflects a higher percentage of females in an elderly population and also a very likely a more equal distribution of risk factors for AMI between both

Table 2

Complications of MI during in-hospital stay.

\begin{tabular}{lccl}
\hline Complication & $\begin{array}{l}\text { Group I Elderly } \\
\text { with AMI } \\
(N=107)\end{array}$ & $\begin{array}{l}\text { Group II Young } \\
\text { with AMI } \\
(N=93)\end{array}$ & $P$ value \\
\hline CCF $^{\text {a }}$ & $70(65.42 \%)$ & $34(36.56 \%)$ & $0.001^{\#}$ \\
Cardiogenic shock & $9(8.41 \%)$ & $2(2.15 \%)$ & 0.0652 \\
Arrhythmia & $53(49.53 \%)$ & $28(30.11 \%)$ & $0.0061^{\#}$ \\
Recurrent MI & $10(9.34 \%)$ & $3(3.23 \%)$ & 0.09 \\
CVA $^{\text {b }}$ & $4(3.74 \%)$ & $1(1.07 \%)$ & 0.3749 \\
Bleeding complication & $5(4.67 \%)$ & $1(1.07 \%)$ & 0.2186 \\
Death & $30(28.04 \%)$ & $8(8.6 \%)$ & $0.0005^{\#}$ \\
No complication & $25(23.36 \%)$ & $48(51.61 \%)$ & $0.0001^{\#}$ \\
\hline
\end{tabular}

${ }^{\#} P$-value $<0.05$ significant.

a $\mathrm{CCF}=$ congestive cardiac failure.

b $\mathrm{CVA}=$ cerebrovascular accident.
Table 3

Various arrhythmias observed during in-hospital stay in both groups.

\begin{tabular}{lcll}
\hline & $\begin{array}{l}\text { Group I Elderly } \\
\text { with AMI } \\
(N=107)\end{array}$ & $\begin{array}{l}\text { Group II Young } \\
\text { with AMI } \\
(N=93)\end{array}$ & P value \\
\hline $\begin{array}{l}\text { Arrhythmias } \\
\text { Type of arrhythmias }\end{array}$ & $53(49.53 \%)$ & $28(30.11 \%)$ & $0.0061^{\$}$ \\
VPB $^{\mathrm{a}}$ (Lowns grading) & & & \\
Grade I $_{\text {Grade II }}$ & $1(0.93 \%)$ & $1(1.07 \%)$ & 1.0 \\
Grade III & $7(6.54 \%)$ & $3(3.22 \%)$ & 0.3437 \\
Grade IV & $4(3.74 \%)$ & $1(1.07 \%)$ & 0.3749 \\
Grade V & $1(0.93 \%)$ & $0(0 \%)$ & 1.0 \\
SVT & $0(0 \%)$ & $0(0 \%)$ & 1.0 \\
AF & $1(0.93 \%)$ & $3(3.22 \%)$ & 0.3396 \\
AV block & $3(2.8 \%)$ & $4(4.3 \%)$ & 0.7068 \\
1st degree block & $22(20.56 \%)$ & $6(6.45 \%)$ & $0.0042^{\$}$ \\
2nd degree block & $4(3.74 \%)$ & $1(1.07 \%)$ & 0.3749 \\
Complete block & $4(3.74 \%)$ & $4(4.3 \%)$ & 1.0 \\
LBBB $^{\mathrm{d}}$ & $14(13.08 \%)$ & $1(1.07 \%)$ & $0.0009^{\$}$ \\
VT/VF $^{\mathrm{b}}$ & $12(11.21 \%)$ & $7(7.53 \%)$ & 0.4710 \\
\hline
\end{tabular}

$\$ P$-value $<0.05$ significant.

a $\mathrm{VPB}=$ ventricular premature beat.

b $\mathrm{SVT}=$ supraventricular tachycardia.

c $\mathrm{AF}=$ atrial fibrillation.

d $\mathrm{LBBB}=$ left bundle branch block

e $\mathrm{VT} / \mathrm{VF}=$ ventricular tachycardia/ventricular fibrillation 
Table 4

Treatment of MI.

\begin{tabular}{lcll}
\hline Treatment & $\begin{array}{l}\text { Group I Elderly } \\
\text { with AMI } \\
(N=107)\end{array}$ & $\begin{array}{l}\text { Group II Young } \\
\text { with AMI } \\
(N=93)\end{array}$ & $P$ value \\
\hline Aspirin & $102(95.33 \%)$ & $91(97.85 \%)$ & 0.45 \\
ACE-I & $72(67.3 \%)$ & $69(74.2 \%)$ & 0.35 \\
Beta-blockers & $18(16.82 \%)$ & $56(60.22 \%)$ & $0.0001^{*}$ \\
LMWH $^{\mathrm{b}}$ & $69(64.5 \%)$ & $70(75.3 \%)$ & 0.12 \\
Thrombolysis $_{\text {PTCA }^{\mathrm{c}}}$ & $27(23.23 \%)$ & $44(47.31 \%)$ & $0.0018^{*}$ \\
CABG $^{\mathrm{d}}$ & $5(4.67 \%)$ & $16(17.2 \%)$ & $0.005^{*}$ \\
\hline
\end{tabular}

${ }^{*} P$-value $<0.05$ significant.

a ACE-I = angiotensin converting enzyme inhibitors.

b $\mathrm{LMWH}=$ low molecular weight heparin.

c PTCA = percutaneous transluminal coronary angioplasty.

${ }^{\mathrm{d}} \mathrm{CABG}=$ coronary artery bypass grafting.

genders at high age. ${ }^{16}$ This trend was similarly noted in other study populations. ${ }^{5,17,18}$ One of the possible reasons for this could to be loss of estrogen and its cardio-protective effects in the elderly females. ${ }^{19}$ However, the role of hormone replacement therapy to reduce the risk of coronary artery disease in postmenopausal women is still controversial. ${ }^{19}$

In the elderly, numerous disorders often coexist. Ischemic heart disease, hypertension, diabetes mellitus, chronic obstructive pulmonary disease, chronic renal failure, digestive system disorders, as well as, joint and bone disorders occur more often in this group of patients. The coexistence of several diseases may cause the clinical picture of acute coronary syndrome to be uncharacteristic. In the present study more cases among the elderly population had atypical chest pain (28\%), no chest pain (21.49\%), on admission to hospital as compared to young population (10.75\% and $7.53 \%$ ). Dyspnea and other nonspecific symptoms like giddiness, syncope and palpitation are frequently observed in elderly patients as compared to young MI in the present study. Confusion or altered mental status may be the presenting manifestation of acute MI in up to $20 \%$ of patients over 85 years of age. ${ }^{20}$ It was observed previously that $75 \%$ of patients over 85 with MIs did not complain about chest pain in the acute phase of MI. ${ }^{21,22}$ Even when classic ischemic precordial discomfort is present, it tends to be less severe and less well defined. The elderly appear to have reduced pain perception. ${ }^{23}$ This phenomenon may result from the increase of pain threshold of permanently ischemic sensory nerves, ischemic dysfunction of the cerebral cortex, and dysfunction of the autonomic nervous system. ${ }^{24}$ The last one is very likely exemplified in that the elderly who did not describe chest pain also did not describe sweating, nausea, and vomiting. ${ }^{1}$ The older the population, the more frequently the symptoms of heart failure exacerbation were described in the acute phase of MI. ${ }^{6}$ Typical symptoms of chronic heart failure exacerbation were often accompanied by mental disorders, dizziness, presyncope, and syncope. ${ }^{6}$
Older patients are also more likely to have "silent" or unrecognized MIs compared to younger patients. These facts often result in delays in MI diagnosis in the elderly. The number of elderly subjects arriving within $6 \mathrm{~h}$ of chest pain was significantly less as compared to young subjects (47.66\% versus $72 \%, P<0.05$ ). Such trends have been observed previously. ${ }^{9}$

As reported in other studies, ${ }^{6}$ this study also showed that the young patients were more likely to have STEMI (66.66\% versus $52.34 \%$ ) as compared to the elderly patients.

Among the risk factors evaluation, hypertension, diabetes mellitus and dyslipidemia were just as prevalent in both the young and elderly AMI patients while smoking, obesity and family history of coronary heart disease were more prevalent in the young AMI patients. This low incidence of smoking in elderly is well explained as most of the elderly quit smoking as age advances and also number of females (postmenopausal) increases in elderly group with AMI who are usually non-smokers. The present study observed no risk factor in $34.58 \%$ cases in elderly with MI. Similar observation, ${ }^{25}$ has also been reported by others suggesting age itself is a major risk factor for myocardial infarction. Knowing the prevalence of various modifiable risk factors among the two age groups may help in planning appropriate secondary preventive programs to target the different age groups. Emphasis for the elderly population should be more targeted at better control of hypertension, dyslipidemia and diabetes mellitus, while for the young population, in addition to hypertension and diabetes mellitus, smoking habits and control of obesity should be emphasized.

A striking finding on admission during and after the ICCU stay was the high occurrence rate of heart failure in the group I as compared to group II. It is known that cardiac failure is an important predictor of poor outcome after AMI. ${ }^{26}$ It is also recognized that even with "best practice" interventions, the prognosis for established cardiac failure in the elderly patients remains poor. ${ }^{27}$ Also, the management of cardiac failure in elderly patients is often complicated by multiple comorbid conditions, polypharmacy and the difficulty in tolerating recommended target doses of drugs. 27,28 Therefore, future research should be aimed at developing more effective strategies for prevention of cardiac failure in elderly patients. In the present study, the next common complications observed in elderly with MI were AV blocks as compared to young with MI. This is not related to differences in location and extent of myocardial necrosis and ischemia. In aging persons, the atrio-ventricular conduction system is subject to spontaneous fibrosis and more vulnerable to ischemia and necrosis. ${ }^{29}$

Despite the fact that older patients constitute the group of high coronary risk and that numerous observations and studies proved that these patients benefit significantly from $\mathrm{PCI}$ in acute $\mathrm{MI},{ }^{30,31}$ invasive procedures in this group of patients are performed relatively rarely. This was consistent with our observations. PTCA was performed in 5 (4.67\%) elderly patients and 16 (17.2\%) younger ones,

Table 5

Thrombolytic therapy for patients with acute onset LBBB and STEMI.

\begin{tabular}{|c|c|c|c|}
\hline & $\begin{array}{l}\text { Group I elderly with AMI with STEMI }{ }^{\mathrm{a}} / \mathrm{LBBB}^{\mathrm{b}} \\
(N=68)\end{array}$ & $\begin{array}{l}\text { Group II young with AMI with STEMI/LBBB } \\
(N=69)\end{array}$ & $P$ value \\
\hline $\begin{array}{l}\text { Given thrombolytic therapy } \\
\text { Reasons for not giving thrombolytic therapy }\end{array}$ & $27(39.7 \%)$ & $44(63.77 \%)$ & $0.0062^{\#}$ \\
\hline Presentation more than $6-10 \mathrm{~h}$ & $27(39.7 \%)$ & $18(26.08 \%)$ & 0.1036 \\
\hline Collapsed requiring prolonged resuscitation & $5(7.35 \%)$ & $2(2.29 \%)$ & 0.2744 \\
\hline Refused/non affording & $3(4.41 \%)$ & $1(1.45 \%)$ & 0.3658 \\
\hline Stroke & $4(5.88 \%)$ & $1(1.45 \%)$ & 0.2084 \\
\hline High systolic blood pressure & $1(1.47 \%)$ & $2(2.29 \%)$ & 1.0 \\
\hline Gastrointestinal Bleed & $1(1.47 \%)$ & $1(1.45 \%)$ & 1.0 \\
\hline
\end{tabular}

${ }^{\#} P$-value $<0.05$ significant.

a STEMI = ST segment elevation myocardial infarction.

b LBBB = left bundle branch block. 
which made the difference statistically significant. Even thrombolysis is applied less frequently in the elderly (23.23\% versus $47.31 \%$; $P<0.05$ ) because of contraindications and the diagnosis delay that causes exceeding of the therapeutic "window" of $12 \mathrm{~h}$. Although several studies, ${ }^{32,33}$ proved that elderly patients benefit from reperfusion therapy, they received both thrombolytic and invasive procedures less frequently when compared with younger patients. ${ }^{30,31}$ This paradox phenomenon was observed in many clinical studies and registries, ${ }^{33}$ and was confirmed in our study well.

The elderly AMI patients were as likely to receive anti-platelet agents and ACE inhibitors. This is a healthy trend. The elderly were, however, less likely to receive $\beta$-blockers compared to the young (16.82\% versus $60.22 \% ; P<0.05$ ). This trend was also noted in another study. ${ }^{34}$ Advanced age, presence of obstructive airway disease, diabetes and congestive cardiac failure have limited the use of $\beta$-blockers in the present study. However more research is needed to evaluate the use and tolerability of $\beta$-blockers in elderly patients with the aim of increasing the usage of $\beta$-blockers in elderly patients to improve outcome after AMI.

In the present study, the overall mortality in elderly with MI was found to be higher than young. Structural changes of the heart related to the process of aging contribute to a great extent to the high early and late mortality of AMI in the aged. In the aged, the adaptations of cardiovascular system to stress is impaired as a consequence of anatomical, functional and metabolic changes in the heart itself and also increase in impedance to ventricular ejection due to anatomical changes in the arterial bed and insufficient vasodilatory capacity of the peripheral vessels. These ages related changes hamper normal ventricular functions and its adaptive mechanisms to the hemodynamic burden elicited by myocardial necrosis. This explain why ventricular dysfunction occurred more frequently in the very elderly patients before and during an AMI. ${ }^{35}$ However age related changes in other organs and deterioration of their adaptive mechanisms to ventricular failure also play a role.

\section{Conclusion}

In conclusion, our observations confirmed the differences in the clinical picture of MI between older and younger individuals in many aspects. The elderly present less typical symptoms of MI, which is followed by the significant delay in diagnosis and initiation of the treatment. This group also has different cardiac risk factor profile characteristics. Despite the fact that the elderly constitute a group at high cardiovascular risk, the most effective methods of MI treatment, such as reperfusion procedures including PTCA, are performed significantly less often when compared to younger MI patients. The majority of differences noticed in our study have been observed previously.

\section{Conflicts of interest}

\section{All authors have none to declare.}

\section{References}

1. Bayer AJ, Chadha JS, Farag RR, Pathy MS. Changing presentation of myocardial infarction with increasing old age. J Am Geriatr Soc. 1986;34:263-266.

2. Tresch DD, Brady WJ, Aufderheide TP, Lawrence SW, Williams KJ. Comparison of elderly and younger patients with out-of-hospital chest pain. Clinical characteristics, acute myocardial infarction, therapy and outcomes. Arch Intern Med. 1996;156:1089-1093.

3. Wang SW, Ren GC, Shio SF, Yu SY, Zhen FY. Acute myocardial infarction in elderly Chinese. A clinical analysis of 631 cases and comparison with 389 younger cases. Jpn Heart J. 1998;29:301-307.

4. Day JJ, Bayer AJ, Pathy MS, Chadha JS. Acute myocardial infarction: diagnostic difficulties and outcome in advanced old age. Age Ageing. 1987;16:239-243.

5. Yang XS, Willems JL, Pardaens J, De Geest H. Acute myocardial infarction in the very elderly. A comparison with younger age groups. Acta Cardiol. 1987;42:59-68.
6. Paul SD, O'Gara PT, Mahjoub ZA, et al. Geriatric patients with acute myocardial infarction: cardiac risk factor profiles, presentation, thrombolysis, coronary interventions and prognosis. Am Heart J. 1996;131:710-715.

7. Mehta RH, Rathore SS, Radford MJ, Wang Y, Wang Y, Krumholz HM. Acute myocardial infarction in the elderly: differences by age. J Am Coll Cardiol. 2001;38:736-741.

8. Reardon M, Camm JA. CME paper: acute myocardial infarction in the elderly. Am J Geriatr Cardiol. 2000;9:138-142.

9. Haase KK, Schiele R, Wagner S, et al. In-hospital mortality of elderly patients with acute myocardial infarction: data from the MITRA (Maximal Individual Therapy in Acute Myocardial Infarction) Registry. Clin Cardiol. 2000;23:831-836.

10. Antman EM, Braunwald E. ST-Segment Elevation Myocardial Infarction. In: Kasper DL, Braunwald E, Fauci AS, Hauser SL, Longo DL, Jameson JL, eds. Harrison's Principles of Internal Medicine. 16th ed. New York: McGraw-Hill; 2005: $1430-1433$.

11. Smith Jr SC. Drug treatment after acute myocardial infarction: is treatment the same for the elderly as in the young patient? Am J Geriatr Cardiol. 1998;7:60-64.

12. Myocardial infarction redefined-a consensus document of the joint European Society of Cardiology/American College of Cardiology Committee for the redefinition of myocardial infarction. Eur Heart J. 2000;21:1502-1513.

13. Resnick NM, Dosa D. Geriatric Medicine. In: Kasper DL, Braunwald E, Fauci AS, Hauser SL, Longo DL, Jameson JL, eds. Harrison's Principles of Internal Medicine. 16th ed. New York: McGraw-Hill; 2005:249-259.

14. Wagner GS. Marriott's Practical Electrocardiography. 11th ed. Philadelphia: Wolters Kluwer Health/Lippincott Williams \& Wilkins; 2008:261-286.

15. De Backer G, Ambrosioni E, Borch-Johnsen K, et al. European guidelines on cardiovascular disease prevention in clinical practice: third joint task force of European and other societies on cardiovascular disease prevention in clinical practice. Eur Heart J. 2003;24:1601-1610.

16. Solomon CG, Lee TH, Cook EF, et al. Comparison of clinical presentation of acute myocardial infarction in patients older than 65 years age to younger patients: the multicenter chest pain study experience. Am J Cardiol. 1989;63:772-776.

17. Kam R, Cutter J, Chew SK, et al. Gender differences in outcome after an acute myocardial infarction in Singapore. Singapore Med J. 2002;43:243-248.

18. Tresch DD. Management of the older patient with acute myocardial infarction: difference in clinical presentations between older and younger patients. $J \mathrm{Am}$ Geriatr Soc. 1998;46:1157-1162.

19. Chew S, Ng SC. Hormone replacement therapy (HRT) and ischaemic heart disease: getting to the heart of the matter. Singapore Med J. 2002;43:41-44.

20. Banach M, Drozdz J, Okonski P, Rysz J. Immunological aspects of the statins' function in patients with heart failure: a report from the annual conference of ESC-heart failure 2005. Cell Mol Immunol. 2005;2:433-437.

21. Akiyama J, Aonuma K, Nogami A, Hiroe M, Marumo F, Iesaka Y. Thrombolytic therapy can reduce the arrhythmogenic substrate after acute myocardial infarction: a study using the signal-averaged electrocardiogram, endocardial catheter mapping and programmed ventricular stimulation. Jpn Circ J. 1999;63:838-842.

22. Muller RT, Gould LA, Betzu R, Vacek T, Pradeek V. Painless myocardial infarction in the elderly. Am Heart J. 1990;119:202-204.

23. Gregoratos G. Clinical manifestations of acute myocardial infarction in older patients. Am J Geriatr Cardiol. 2001;10:345-347.

24. Miller PF, Sheps DS, Bragdon EE, et al. Aging and pain perception in ischemic heart disease. Am Heart J. 1990;120:22-30.

25. Hoit BD, Gilpin EA, Henning $\mathrm{H}$, et al. Myocardial infarction in young patients: an analysis by age subsets. Circulation. 1986;74:712-721.

26. Spencer FA, Meyer TE, Gore JM, Goldberg RJ. Heterogeneity in the management and outcomes of patients with acute myocardial infarction complicated by heart failure: the national registry of myocardial infarction. Circulation. 2002;105:2605-2610.

27. Rich MW. Management of heart failure in the elderly. Heart Fail Rev. 2002;7: 89-97.

28. Lien CT, Gillespie ND, Struthers AD, McMurdo ME. Heart failure in frail elderly patients: diagnostic difficulties, co-morbidities, polypharmacy and treatment dilemmas. Eur J Heart Fail. 2002;4:91-98.

29. Stolker JM, Rich MW. Diagnosis and Management of Heart Disease in Elderly. In: Arenson C, Busby-Whitehead J, Brummel-Smith K, O'Brien JG, Palmer MH, Reichel W, eds. Reichel's Care of the Elderly: Clinical Aspects of Aging. 6th ed. New York: Cambridge University Press; 2009:102-122.

30. Matetzky S, Sharir T, Noc M, et al. Primary angioplasty for acute myocardial infarction in octogenarians. Am J Cardiol. 2001;88:680-683.

31. Harpaz D, Rozenman Y, Behar S, Boyko V, Mandelzweig L, Gottlieb S. Coronary angiography in the elderly with acute myocardial infarction. Int J Cardiol. 2007; 116:249-256

32. Kosuge M, Kimura K, Kojima S, et al. Beneficial effect of preinfarction angina on in-hospital outcome is preserved in elderly patients undergoing coronary intervention for anterior acute myocardial infarction. Circ J. 2005;69:630-635.

33. Mehta SR, Cannon CP, Fox KA, et al. Routine vs selective strategies in patients with acute coronary syndromes: a collaborative meta analysis of randomised trials. JAMA. 2005;293:2908-2917.

34. Krumholz HM, Radford MJ, Wang Y, Chen J, Marciniak TA. Early beta-blocker therapy for acute myocardial infarction in elderly patients. Ann Intern Med. 1999;131:648-654.

35. Gerstenblith G, Lakatta EG, Weisfeldt ML. Age changes in myocardial function and exercise response. Prog Cardiovasc Dis. 1976;19:1-21. 